If the difficulty is such in adult life, how much is it increased when the patient is a young child!

The dyspeptic disorders, which form the earlier symptoms, are so frequent in childhood, from other and less serious causes, that their special import is very likely to be overlooked. The headache and weariness which were the other chief general symptoms would of course, unless the disease had been recognised, be reconciled with the erroneous conception of the nature of the case. The peculiar pallor seems to me, in looking back, to be the most marked and characteristic of the early signs, and perhaps this, in conjunction with the headache and vomiting, ought to have aroused earlier suspicion; but, on the other hand, there was the absence of any trace of dropsy, no puffiness of the eyelids, or of the feet, and, most misleading of all, the absence of proof upon testing the urine for the presence of albumen. Dr. Geo. Johnson has recorded that, of 33 cases of granular kidney, there was no dropsy whatever in 14, while in many of the remainder it was of the slightest character; and Dickinson states that of 68 cases, 19 " went to their graves with granular degeneration, without dropsy at any period of the complaint" (op. cit., p. 129). As to the latter and most important fact, Dickinson says (op. cit., p. 139), "Early in the disease the urine is free both from albumen and casts." Dr. Geo. Johnson also says of the urine in the early stages of this condition, "In quantity, specific gravity, and colour, it differs very little, if at all, from the standard of health; it is perhaps more acid than usual, but contains not a trace of albumen." It is of interest, regarding the history of this case and the well-marked polyuria in the early stage, to quote Dr. Dickinson a little further. He says (op. cit., p. 128), "It (the urine) is passed more often natural, especially at night, apparently in consequence of its increased quantity, not because it has acquired any irritating quality." If examined in this early stage, it may be found perfectly free from albumen, or it may contain only a minute trace." Now at this time the diuresis was the principal symptom in the eyes of the parents and attendants, and was very marked, not only at night, but also in the daytime, so that the urine would run from the child as she walked across the floor, and she was obliged to wear napkins. There was no irritability, but simply a frequency of micturition, from the great quantity of water entering the bladder. Dr. W. Roberts, in his valuable work on Renal Diseases, says, on the other hand, "Absolute freedom from albumen, even for short intervals, is very rare. I am convinced that a considerable number of the cases so reported are examples of imperfect testing. When the quantity of albumen is extremely small, nice management is required to detect it. Heat is insufficient. Nitric acid should be allowed to trickle slowly to the bottom of the test-tube, and some minutes allowed to elapse in order to develop the hazy zone above the level of the acid." Dr. Roberts is in this place speaking of Bright's disease generally; elsewhere, in speaking of granular kidney, he says, "In rare cases it (albumen) may even be temporarily absent from the urine." Now I enjoyed the privilege of instruction in urinary examination by Dr. Roberts, and habitually use the method described, yet in the early stage (May, 1872) I did not detect any albumen.

The whiteness of the conjunctiva struck me as the result of contrast with the peculiar brownish colour of the skin, and had not the appearance of œdema at all, but rather a hard, steely glitter. The deafness is a rare symptom. In so young a child we cannot make sure that the sight was not affected, but no complaint was made, nor was anything noticed by the attendants that would lead to such a belief. The solitary convulsion which occurred in February was not seen by any medical man. Dr. Roberts says upon this subject, "An attack of uræmic convulsions may consist of only a single paroxysm. ...... If a first attack does not prove fatal, it may recur at irregular intervals of weeks or months, or be replaced by uræmic symptoms of some other order." * The final scenes of a succession of strong epileptiform convulsions, with short intervals of quiet coma, gradually be. coming shorter until death, form a history agreeing exactly with Dr. George Johnson's description of one mode of death from this disease (op. cit., p. 197).

There are several points of interest in the post-mortem appearances.

Firstly, we may notice the presence of vesicular emphysema in the lungs - a point which, unless it is included

$$
\text { * Renal Diseases, 1st edit., p. } 249 .
$$

under the head of bronchitis, is mentioned distinctly by but few of the writers whose works have fallen under my notice. Christison, however, mentions it as a frequent concurrent of granular degeneration of the kidney; and Sir William Gull and Dr. Sutton, in their previously quoted paper (Medico-Chirurgical Transactions, vol. lv.) say: "It is well known that vesicular emphysema and granular contracted kidneys frequently coexist. Of 33 cases of persons about middle age in which the lungs were emphysematous, the kidneys were more or less granular and contracted in 22." And further: "In some of the cases the emphysema was great, while the kidneys were only slightly granular; in other cases the kidneys were much contracted, while the Iungs were comparatively little diseased: which facts seemingly show that the emphysema may precede the kidney contraction, or the kidney disease may occur antecedent to the lung disease; and this is fully borne out by clinical experience." Our authors would seem to form a different estimate of the frequency of this complication from that to be derived from the table published in Dr. W. Roberts work on Renal Diseases. Of 406 autopsies tabulated there (2nd edit., p. 406), only 33 are reported as showing evidence of vesicular emphysema ; and Dr. Dickinson, in a table of 68 autopsies under his own observation, where the patients had died from granular degeneration of the kidneys, though he gives 24, in which bronchitis was present, yet does not mention empbysema.

The condition of the spleen is another point of great interest in this case. Grainger Stewart mentions that he found thickening of the capsule of the spleen and increase of the fibrous stroma in 40 per cent. of the cases be examined. Sir W. Gull and his confrère state that in these cases they have found the spleen to be "diminished in size, the capsule thickened, on section substance tougher than natural; but the most noticeable alteration was the increased quantity of fibrous tissue. Under the microscope the vessels were seen surrounded by a much larger quantity of fibroid tissue than usual, and in the outer coats of some of the minute arteries hyalin fibroid changes were obvious, and similar to such as occur in the arteries of the kidney and pia mater." Dickinson found thickening of the capsule of the spleen in one-fifth of his cases. The vomiting of blood, like the more usual epistaxis, in these cases, was doubtless due to the high tension of the pulse and the increased arterial pressure. The liver in this case appeared to be normal to the naked eye, but nnder the microscope there was seen a distinct deposit of fibroid strncture around the lobules. Grainger Stewart found cirrhosis of the liver in 15 per cent. of his cases of granular kidney, and this proportion also agrees with that found by Dickinson-viz., 1 in 7. Christison says " the conjunction of disease in the liver is perhaps even more frequent than that of diseased heart."

(To be concluded.)

\section{ON THE RESTORATIVE TREATMENT OF DELIRIUM TREMENS.}

\section{Br AR'THUR E. T. LONGHURST, M.D., 4TH BATT. 60 $\mathrm{nH}$ RIFLES.}

WHILst desirous of bringing to the notice of the profession the restorative treatment of delirium tremens, I do not wish to occupy time or space by any dissertation on the exact physiological state of the system under which the affection shows itself, nor of the pathology which characterises the attack. For opinions are, I think, pretty well agreed in considering the affection to be one of "nervous exhaustion," originating in whatever causes may conduce to that state, the chief and immediate cause being doubtless a poisoned condition of the blood due to the presence of accumulated and decomposing alcohol in the system; and hence in the nomenclature of disease the affection is now very fitly classed under the head of "poisons,"-and the symptoms, though varied, are easily recognisable. But whilst opinions concur in both the causes and symptoms of the disease, they may be said to differ much as to treatment; and we occasionally still find advocates of some one or other of the old plans-e.g., antimony and opium, or 
opium alone (in one or other form and in large doses), digitalis, chloroform, and even alcohol, on the principle of "a hair of the dog that bit you."

A somewhat lengthened experience of the affection in the service, and a study of its symptoms in a variety of climate, have convinced me that such remedies are both mistaken in principle and dangerous in practice; and though unhappily, during the early part of my professional career, whilst carrying out the principles taught in the schools during the time of my studentship, I can call to mind the fatal termination of cases treated by one or other of the old plans, I am glad to think that I have not experienced a fatal case for years past. Indeed, I should now hold myself almost criminally reponsible for the death of a patient treated by any of the old remedies in the somewhat heroic and oft-repeated doses formerly prescribed; especially either opium or alcohol, not a grain nor a drop of which have I given in the treatment of the affection for several years. And, with the blood already poisoned by alcohol, it cannot, I am persuaded, be right to intensify that condition by more alcohol, opium, or any other sedative narcotic, thus subjecting the system to two powerful poisons at the same time, whereby the ganglionic nervous system must be still further oppressed. It is in this way, I think, that we may explain tbe occasional sudden and fatal termination of cases after surgical operations where morphia has too speedily followed upon chloroform, and in the treatment of disease where the hypodermic injection of morphia bas been employed in the delirium of fevers or other form of blood poisoning.

The principles, then, which I would advocate for the treatment of delirium tremens $I$ will arrange in degree of importance in the following order: -1 . The elimination of the poison from the system. 2. The restoration of exhausted nerve-power, by the administration of nourishment, and that of a kind most easily and rapidly assimilated. 3. The induction of sleep.

I will now endeavour to point out the method by which the application of the above principles may be best and quickest fulfilled. And I think that the fewer medicines we employ, the better it will be for our patients; whilst in water, especially in the form of a bath, in milk and eggs, we have doubtless both powerf ul and invaluable remedies.

To fulfil the first indication - the elimination of the poison from the system-we must have recourse to those remedies which, whilst they promote the eliminating power of the skin, lungs, bowels, and kidneys, are not too depressant. Thus the skin may be well acted upon by a tepid or even by a cold bath, according to the strength of the patient, the precise nature of the case under observation, and the season of the year, followed by friction and rubbing with a course towel, the good effect of which can hardly be overrated; for whilst the skin is thereby relieved of alcoholic perspiration and other effete matter from the blood, the sentient extremities of the nerves are roused to more vigorous action, and respiration is rendered temporally more active. A tumbler of cold water given on entering the bath materially increases its efficacy. Of the medicinal remedies best calculated to promote the moderate action of the organs named, none are perhaps better than the com. pound jalap-powder in conjunction with nitric spirit of ether; and I have usually found one or at most two doses of two drachms of the former and half a drachm of the latter effectually to relieve both the bowels and kidneys.

The second indication for treatment-the restoration of nerve-power-will be found best and most readily accomplished by the administration of warm milk, either alone or with eggs beaten up in it; for, containing as it does every element of nutrition most easily assimilated, it is singularly calculated to repair nervous power and energy; and if we can once succeed in getting our patient to take a quarter or half a pint of warm milk, either alone or with the yelk of an egg beaten up in it, we need scarcely any longer be apprehensive as to the issue of the case, and we can then give a mutton chop or other solid food, which will be another great point gained. It is, however, most important that the milk be taken warm, in order to ensure its rapid and easy digestion. If there is stomach irritability, it must of course be met in the usual way; and if obstinate (though I have not had occasion to try it), I should anticipate the best results from a bladder of ice to the epigastrium, as calculated to restore tone to the nervous system through the especial medium of the solar plexus and the other sympathetic ganglia.

As regards the third principle of treatment-the induction of sleep: having in some measure fulfilled the two former-namely, the eradication of the poison from the system, and the partial restoration of nerve-force by the assimilation of nourishment,一we have doubtless gained a great point in this direction; and, desirable as sleep may be, still I do not advocate the use of many medicines with that object, and I think that in chloral hydrate we have nearly all we want. Indeed, I have so of ten found that the sleep induced by medicines, especially any form of sedative narcotic, has not been followed by any permanent subsidence of delirium or other urgent symptom; and, from the very transient good effects of sleep thus artificially induced, I am disposed to think that too much stress has been laid upon its importance, and that the value of nourishment in the treatment of delirium tremens has been overlooked.

I shall not here occupy space by the report of cases in supprrt of the above belief, though almost the last case under treatment very forcibly confirmed it; for though several hours of good sound sleep had followed the admi. nistration of half a drachm of chloral bydrate, the patient's condition was alarmingly prostrate until egg and milk had been assimilated. Hence I am persuaded that, having once secured the digestion and assimilation of food, we may be less anxious about sleep, and rest satisfied by placing our patient under conditions favourable for it; whilst chloral, judiciously administered, either alone or in milk or some other form of liquid nourishment, is almost the only medicinal hypnotic that $\mathrm{I}$ would advocate.

Having thus endeavoured to indicate what appears to me to be a rational method for the treatment of delirium tremens, on the principles set forth in the order named, I feel that these require a liberal interpretation; for doubtless the greatest success in the treatment of this affection, as of most others, will follow the ready appreciation of the most urgent symptoms in this or that particular case. Hence it may be sometimes necessary to disregard the first principle, and at once to direct our efforts to the attainment of the second, by the administration of nourishment; and even to anticipate the third, by placing the patient under conditions favourable to sleep. In like manner, much can be done by judicious general management-by humouring the whims and fancies of a patient, when not of a dangerous character or tendency, and so long as he is carefully watched. Instead of confining a sufferer to the recumbent posture in bed, he may be allowed to be up, to walk about, and to engage in conversation and harmless amusement, whilst the process of digestion and assimilation is going on, or until sleep comes naturally.

Verne Citadel, Portland.

\section{d e dettrtor}

\section{H O S P T A L PRACTICE,}

\section{BRITISH AND FOREIGN.}

Nulla autem est alia pro certo noscendi via, nisi quamplurimas et morborum et dissectionum historias, tum aliorum, tum proprias collectas habere, et inter se comparare.-Morgagrr De Sed, et Caus. Morb., lib. iv. Procemium.

\section{UNIVERSITY COLLEGE HOSPITAL.}

A CASE OF DISLOCATION BETWEEN THE SECOND AND THIRD CERVICAL VERTEBRA； DEATH ON THE FOURTH DAY; CLINICAL REMARKS.

(Under the care of Mr. ERICHSEN.)

For the notes of the following interesting case, and for the report of Mr. Erichsen's clinical remarks, we are in. debted to Mr. Maclean, house-surgeon.

W. W-, aged thirty-four, a carpenter, was admitted May 16th, for injuries sustained while getting out of a train before it had stopped, by falling between the platform and the carriages. When picked up he was sensible, and complained of pain in his right arm; and it was noticed that he had had a fæcal motion.

On admission, he was found in the following condition:- 